\title{
El ‘Granero de Chile': Una ecología política histórica de la construcción de un paisaje de poder en Wallmapu (Araucanía)'
}

\section{The 'Chilean wheat bowl': An historical political ecology of the construction of a landscape of power in Wallmapu (Araucanía)}

\author{
Miguel Escalona Ulloa² (1) y Jonathan R Barton³ [i]
}

\begin{abstract}
RESUMEN
El paisaje de poder del 'Granero de Chile' emerge durante el siglo XIX como un símbolo del progreso en Wallmapu (Araucanía). El Estado chileno, apoyado por las élites agrícolas, políticas e intelectuales movilizaron acciones que permitieron la explotación de los recursos naturales. Estos acontecimientos posibilitaron la construcción del paisaje de poder del 'Granero de Chile', que se instaló en la antigua frontera araucana. Mediante la deconstrucción e interpretación de fuentes históricas y utilizando la perspectiva de la ecología política histórica y los paisajes de poder, se indaga en su trayectoria la cual está vinculada a una hegemonía imperante que se traza a través de dispositivos para ejercer la coerción, lograr el consentimiento e imponer una forma particular de paisaje en este territorio. Las conclusiones apuntan a la importancia del contexto histórico para explicar las configuraciones socioecológicas contemporáneas de paisajes, ya que permiten comprender la influencia de las relaciones de poder y los factores políticos, económicos y culturales en la construcción social de un territorio, y en la eliminación de otros paisajes.
\end{abstract}

Palabras claves: Paisaje de poder, Ecología política histórica, Granero de Chile, Wallmapu (Araucanía)

\begin{abstract}
The landscape of power of the 'Chilean wheat bowl' that emerged during the nineteenth century was presented as a symbol of progress for Wallmapu (Araucanía). The Chilean state, supported by agrarian, political and intellectual elites enabled the extraction of natural resources which led to the construction of a new 'Chilean wheat bowl' landscape of power, installed on the old Mapuche frontier. This article deconstructs and interprets historical sources within a framework based on historical political ecology and landscapes of power. It traces the hegemonic imposition of this landscape via devices that ensured coercion or enabled consent, with a view to imposing a particular landscape in this territory. The conclusions point to the importance of historical context for explaining contemporary socio-ecological configurations of landcapes, since this context reveals the influence of power relations and political, economic and cultural factors in the social construction of territories, and the elimination of other landscapes.
\end{abstract}

Keywords: Landscape of power, Historical political ecology, the Chilean wheat bowl, WaIlmapu (Araucanía). 


\section{RESUMO}

O paisagem de poder do "Granero do Chile" surgiu durante o século 19 como um símbolo do progresso em Wallmapu (Araucanía). O Estado chileno, apoiado pelas elites econômicas, políticas e intelectuais, mobilizou ações que permitiam a exploração de recursos naturais. Esses eventos possibilitam a construção do paisagem de poder do "Granero do Chile", instalado na antiga fronteira araucana. Através da desconstrução e interpretação de fontes históricas e utilizando a perspectiva da ecologia política histórica e paisagens de poder, é investigada a trajetória a qual está ligada a uma hegemonia predominante que é traçada através de dispositivos para o exercício da coerção, alcançar o consentimento e impor uma forma particular de paisagem neste território. As conclusões apontam para a importância do contexto histórico para explicar as configurações sócio-ecológicas contemporâneas, pois permitem compreender a influência das relações de poder e fatores políticos, econômicos e culturais na construção social de um território

Palavras-chave: Paisagem do poder, Ecologia política histórica, Granero do Chile, Wallmapu (Araucanía)

La historia territorial chilena documenta una serie de usos intensivos que han generado transformaciones profundas en el paisaje y las poblaciones locales, desde la minería de salitre del norte y la producción ovina de Magallanes, hasta la salmonicultura de Los Lagos y la industria vitivinícola de la Región de O'Higgins. Muchas veces estas transformaciones son presentadas como acciones asociadas al progreso y desarrollo, a partir de su aporte a la economía nacional. Sin embargo, estas también reflejan luchas de poder sobre la definición de estos territorios, sus vocaciones y medios de vida. La ecología política histórica permite representar las historias territoriales como construcciones sociales basadas en relaciones de poder generadas entre grupos determinados. En este sentido, se puede definir un paisaje como una construcción social de una transformación de la naturaleza, basada en una visión creada e impuesta. De esta forma es posible señalar que los cambios en los paisajes son siempre impuestos, a menudo con fuerza o sino con una gran variedad de dispositivos, que incluyen la ciencia, la legislación, y también discursos que los redefinen. La perspectiva crítica para analizar los paisajes regionales, resulta clave para expresar no solamente la visión del progreso definida por las elites en la construcción del país, sino para revelar las alternativas de desarrollo suprimidas o vencidas en este proceso. El Granero de Chile representa estas visiones, mientras el paisaje del salitre en el norte fue construido basado en un modelo de explotación extranjera, el Granero fue la primera transformación de gran escala impulsada por el estado chileno.

Uno de los dispositivos utilizados para crear un paisaje es el acto de nombrarlo. La creación de 'La Araucanía' como una región, un invento del Estado chileno en su propio lenguaje (y en referencia a sus mismos habitantes), resulto determinante para resignificar esta región. Por ello, en este artículo se usa la palabra de los mismos habitantes previo a la definición del Estado chileno: Wallmapu, y Araucanía de forma parentética, simbolizando el paisaje impuesto sobre ello.

Este trabajo propone una reflexión respecto del paisaje a partir de su relación con el poder. Busca posicionar al paisaje como un constructo histórico, interesado e imprescindible para comprender los conflictos contemporáneos que ocurren en algunos espacios regionales. Para alcanzar tal objetivo, se revisitan y tensionan las principales corrientes y conceptualizaciones que han estado involucradas en su estudio, con el propósito de plantear una mirada distinta asociada a los 'paisajes de poder'. Este marco de análisis es puesto a prueba a través del 'Granero de Chile', paisaje que surge a finales del siglo XIX producto de un activo rol del Estado y las elites agrícolas, 
políticas y científicas de la época, quienes promovieron un sentido común dominante centrado en la vocación productiva y la explotación de estas tierras.

La revisión de fuentes no fue solo documental, sino que incluyó también la interpretación de mapas y fotografías, además, se utilizo como campo de investigación la ecología política histórica (Offen, 2004) que busca explicaciones históricamente situadas a los conflictos contemporáneos considerando las relaciones de poder y los factores políticos, económicos y culturales que se transmiten hacia el presente y comprometen el futuro (Davis, 2009, 2015, 2016). Con esa diversidad de fuentes fue posible establecer que dicho paisaje se construyó sobre una espacialidad y forma de habitar mapuche que fue invisibilizada a partir del despliegue de dispositivos inmateriales -discursos- y materiales -colonización, conquista y civilización- que transformaron este espacio a partir de la llegada del ferrocarril, la fundación de ciudades y el arribo de una elite económica.

La trayectoria de este paisaje y los dispositivos utilizados en su construcción (ver Foucault, 1984), se presentan en este artículo a través de tres secciones. En la primera de ellas, se realiza una discusión respecto al paisaje, sus diferentes definiciones y se proponen también nuevas interpretaciones. La segunda sección indaga en las formas de habitar el paisaje por parte del pueblo mapuche que se caracteriza por el sentido de libertad en la ocupación y administración del espacio. Luego, la discusión aborda el rol del Estado, las elites y los dispositivos utilizados para construir el paisaje de poder del 'Granero de Chile', entre los cuales destacan: la promulgación de leyes, los discursos centrados en la 'vocación productiva' de este lugar y la conquista del Estado chileno sobre Wallmapu conocida eufemísticamente como 'pacificación de la araucanía' (Saavedra, 1870; Bengoa, 2000; Pinto, 2003). Este acápite busca reconocer un paisaje anterior, un 'antes' previo a la transformación de este lugar.

La última sección se sitúa en el Granero de Chile propiamente tal y hace énfasis en la explotación de las tierras, la llegada del ferrocarril, la fundación de ciudades y el arribo de una elite agrícola, acciones que terminaron por favorecer un colonialismo sistemático sobre el pueblo mapuche. Las conclusiones se orientan a establecer la relevancia de considerar el paisaje como una categoría de debate político, cuya expresión espacial permite comprender las diversas aristas involucradas en las transformaciones y conflictos territoriales que se mantienen hasta nuestros días. Además, se plantea que los paisajes son construcciones sociales basadas en visiones creadas e impuestas, y por naturaleza son contra-puestas con otras alternativas, incluso los medios de vida y usos existentes. Son las relaciones de poder entre diversos grupos de actores que terminan facilitando la implementación de un paisaje por sobre otro. Es por esta razón que el concepto mismo de paisaje, y las transformaciones territoriales de Chile, deben ser entendidas como luchas de definición, de control y de resistencias, y no como vocaciones territoriales neutrales al servicio de una narrativa de progreso nacional.

\section{El paisaje como punto de partida}

Los enfoques tradicionalmente utilizados en el estudio del paisaje han predominado concepciones antagónicas, vale decir, el paisaje entendido como naturaleza/cultura, material/inmaterial 
o bien donde sólo predominan elementos tangibles (Cassirer, 2014; Muir, 1998; Husserl, 1962; Popper, 1991).

Con el paso del tiempo fue necesario discernir respecto a otros elementos, factores o acontecimientos que están implicados en el paisaje. De esta forma, se fue transitando desde aquellas ideas que planteaban visiones más objetivas o cartesianas respecto al paisaje, hacia ámbitos subjetivos o simbólicos que se enmarcaron en perspectivas más bien fenomenológicas (Sauer, 1925; Lowenthal, 1961; Meinig 1979; Cosgrove \& Daniels, 1988) (Figura №1).

Estas perspectivas, generaron la base para comprender el paisaje desde la vivencia, en el cual el ser humano forma parte de él y se constituye en un agente transformador a partir de sus prácticas cotidianas, nuestra corporalidad y el sentido de lugar, que influye en sus cambios y continuidades (Tuan, 1974; Ingold, 1993; Bhabha, 2002; Simmel, 2012) (Figura Nº1).

En el contexto de estas discusiones, surge otra perspectiva para comprender el paisaje a través de sus vínculos con el poder, la cual propone un enfoque más crítico al reconocer que este se encuentra influenciado por aspectos económicos y políticos (Mitchell, 2001, 2002, 2008). En ellos el rol de la hegemonía (Gramsci, 1999; Femia, 1987; Martin, 2002) resulta clave, ya que refleja las formas en que se ejerce la coerción y el consentimiento para consolidar una forma particular de construcción y ocupación del paisaje que se expresa a través de las transformaciones territoriales (Escalona, 2019; Escalona y Barton, 2020; Escalona 2020) (Figura Nº1).

Figura 1.

Evolución de las perspectivas asociadas al paisaje

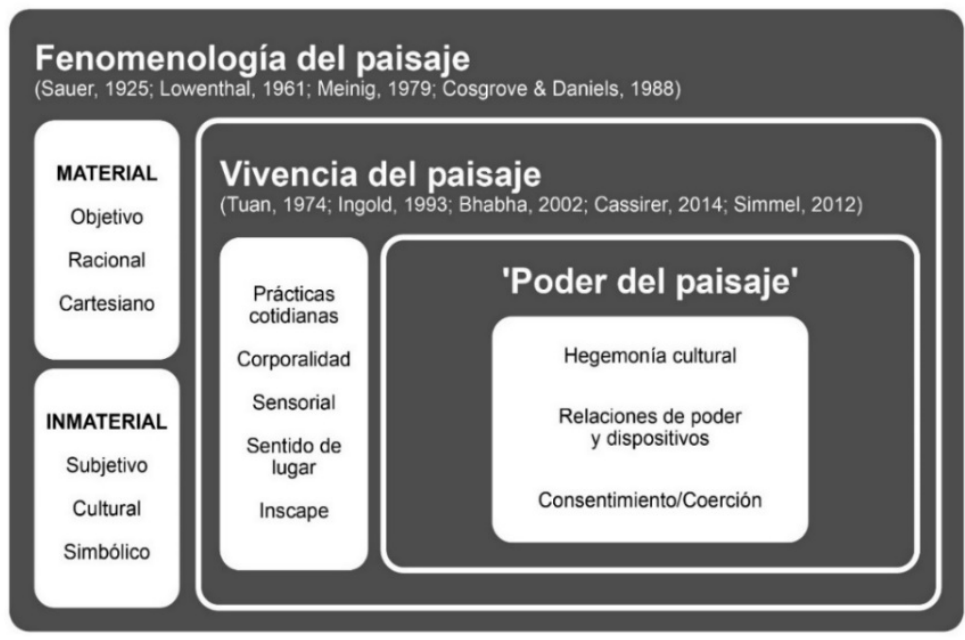

Fuente: Escalona, 2019; Escalona \& Barton, 2020.

Este trabajo plantea que los paisajes de poder son construcciones materiales y simbólicas a la vez, creados en base de ciertas configuraciones de relaciones de poder. Se expresan a nivel territorial no de forma neutra o casual, sino que producto de la hegemonía cultural que, en el caso particular de La Araucanía, ha generado uno de los conflictos históricos más importantes que 
involucra al Estado y al Pueblo Mapuche. El paisaje del 'Granero de Chile' que surge a finales del siglo XIX en Wallmapu (Araucanía) permite poner a prueba esta relación del paisaje con el poder, ya que emerge a partir del anhelo del Estado y las elites agrícolas, políticas y científicas por llevar a cabo la explotación agrícola intensiva de estas tierras y la invisibilización del pueblo mapuche, estas ideas forman parte central de la argumentación utilizada en este trabajo y se sustentan en una profunda revisión e interpretación de fuentes históricas de tipo documental, mapas y fotografías.

\section{Area de estudio y dimensiones metodológicas}

La dimensión escalar de este trabajo sitúa a la región de La Araucanía, ubicada en el sur de Chile, como ámbito central de análisis. El uso de una metodología mixta resultó crucial y consideró no tan solo el análisis e interpretación tradicional de fuentes históricas documentales, sino que también mapas y fotografías, las cuales entregaron información espacial relevante para reconstruir este paisaje. El análisis del discurso fue utilizado para conocer cómo este se estructura y se posiciona en los distintos actores sociales. Para examinarlos se enfatizó en aquellos lenguajes figurativos que hacen que los argumentos sean más o menos efectivos (Rydin, 2003).

El trabajo de campo para llevar a cabo esta investigación se realizó durante los años 2018 y 2019, periodo en el cual fueron visitados diversos centros documentales entre los que destacan, el Archivo y la Biblioteca Nacional ubicados en Santiago, el Archivo Regional de La Araucanía y centros culturales de algunas comunas de la misma región. La búsqueda en cada uno de estos lugares tuvo como propósito seleccionar documentos e identificar palabras claves y relatos que exponen aquellas ideas que sustentaron la construcción del paisaje de poder del 'Granero de Chile'. Para lograr aquello se utilizaron métodos interpretativos que consideran la interacción entre tres elementos: crítica, triangulación y hermenéutica (Donnelly \& Norton, 2011; Kipping et al. 2014).

El análisis e interpretación de mapas permitió identificar los cambios a nivel territorial ocasionados por los dispositivos utilizados para construir este paisaje. Este trabajo consideró que los mapas son representaciones selectivas de la realidad (Schlögel, 2007), de ahí que existan elementos ausentes en ellos que deben ser develados. Para alcanzar tal propósito se buscó 'deconstruir el mapa', teniendo en consideración las reglas cartográficas, el texto cartográfico y el poder interno y externo de ellos (Harley, 1989; Del Casino \& Hanna, 2006; Vermeylen et al, 2012). Por su parte, el estudio de las fotografías fue realizado desde la semiótica, que permite la identificación de ciertos artefactos, vestimentas, a través de las cuales es posible analizar la visión de mundo y el contexto cultural, político, material de la época (Burke, 2001; Kossoy, 2001). La interpretación iconológica, permitió profundizar en las connotaciones perceptivas, cognoscitivas e ideológicas presentes en la fotografía (Barthes, 1986).

\section{El habitar mapuche sobre el paisaje y sus primeras transformaciones}

Las primeras referencias a la forma de habitar el paisaje por parte del pueblo mapuche, surgieron de las descripciones que Alonso De Ovalle realizó en el siglo XVII respecto a estas tierras y sus habitantes, al respecto señalaba: 
"La grandeza de sus jurisdicciones y poblaciones, nunca fueron en forma de ciudades, porque todo lo que olía a algún genero de sujeción o apretura, no les agradaba, sino el desahogo y libertad, allí vivían en los campos cada cacique con sus vasallos, y parcialidad" (De Ovalle, 1646, p. 89).

Esta reseña comunica la 'vivencia' del paisaje del pueblo mapuche, que se caracteriza por una relación estrecha con (en) la naturaleza. Sus costumbres y prácticas culturales quedan expresadas en el tiempo y en el espacio otorgándole un sentido y experiencia a su habitar. Como habitante ancestral de estas tierras se distribuye a lo largo y ancho de ellas, imponiéndose como dominador absoluto.

Relatos posteriores realizados por el Abate Juan Ignacio Molina, enfatizan en su organización territorial:

"Los araucanos dividen todo el largo de este país en cuatro Uthanmapu o Principados paralelos, y casi de un mismo ancho, y a los cuales dan los nombres de Lauquenmapu, esto es, país marítimo, Lelgunmapu, país llano, Inapiremapu, país subandino, y Piremapu, país andino, subdividiendo cada Uthanmapu en cinco Aillarehue ó Provincias, y cada Aillarehue en nueve Rehues ó prefecturas" (Molina, 1788, p. 14)

La organización territorial utilizada por el pueblo mapuche para ocupar el espacio se basa en algunos hitos geográficos- mar y cordilleras-, que junto con delimitar cada 'Uthanmapu', entregan identidad a quienes lo habitan.

Ambos cronistas transmiten una forma estructurada de habitar el paisaje. Esto se debe a la visión de mundo de aquella época, ya que ellos utilizaban categorías fijas para analizar el entorno, por lo tanto, la vivencia del pueblo mapuche se menciona siempre siguiendo un orden establecido. Estas descripciones cambian en aquellos relatos provenientes del pueblo mapuche. Es el caso del cacique Pascual Coña, quien habitó en la costa entre 1840 y 1927. Sus experiencias fueron escritas por Ernesto Wilhelm de Moesbach, misionero capuchino quien las publicó ya entrado el siglo XX. En ellas se señala:

“Rauquenhue, mi tierra natal, está situada a orillas del Océano Pacifico. Al lado opuesto a este se halla un hualve cubierto de totora, el cual en ambos extremos comunica con el lago de Budi. En el lado de acá hay una porción de tierra rodeada de agua, la isla Huapi. Al norte Rauquenhue deslinda con Deume y al sur se extiende hasta Puauchu" (Moesbach, 1930, p.28)

El paisaje descrito por Coña hace énfasis en aquellos lugares que forman parte de su vida cotidiana junto al mar. Los hualves o humedales, el lago Budi, la isla Huapi, son descritos con gran prolijidad y dan cuenta de la interacción permanente entre el pueblo mapuche y su entorno.

Estas formas de uso del espacio no resultaban propicias para llevar a cabo la explotación del Wallmapu (Araucanía), tampoco para acumular capital, por ello, transitar hacia un paisaje 'productivo' resultaría crucial para reemplazar esta forma de habitar que se caracterizaba por prácticas comunitarias, por otra donde predominaría la propiedad privada y la explotación intensiva de la 
tierra. El Granero de Chile vendría a materializar los imaginarios construidos respecto a este lugar, por parte del Estado y las elites de la época.

\section{El paisaje de la colonización y la conquista}

Los movimientos sociales surgidos en diversos continentes que buscaban combatir la fase expansiva del capitalismo, generaron desequilibrios en el mercado internacional impactando de manera significativa a las elites chilenas (Humud, 1947; Grez, 2007). En este contexto, la guerra del pacifico fue un hecho que permitió unir al país en un nacionalismo exacerbado donde la bendición del salitre le otorgó a esta clase dirigente un respiro importante en el plano económico, político y social (Ortega, 1984). Los resultados de esta guerra facilitaron que la actividad salitrera se constituyera en el pilar de la economía exportadora chilena y situó también a la agricultura en un contexto socioeconómico extremadamente dinámico (Cariola \& Sunker, 1982; Robles, 2009).

En este contexto, no resultaría extraño que desde las primeras décadas del siglo XIX se 'mirara' con atención las tierras ubicadas al sur del país (Bengoa, 2000; Pinto, 2003). Los naturalistas tuvieron un rol importante en este proceso ya que a partir de sus travesías lograron penetrar al interior de la 'frontera', con el propósito de descubrir su naturaleza exuberante la cual se encontraba sin explotar. Uno de ellos fue Ignacio Domeyko quien señalaba:

"El árbol más abundante, que ejerce un dominio universal en toda la extensión de las indicadas montañas, es el roble (Fagus dobeyi, Mirbel; australis, Pöeppig). Su madera, según Pöeppig, iguala en calidad a la de las encinas de Inglaterra y de Norteamérica" (Domeyko, 1846, p. 17).

Para Domeyko, la naturaleza araucana es un recurso natural que puede ser incorporado en algún proceso productivo, el grosor de los árboles y la posibilidad de transformarlos en madera, son los elementos principales que surgen de este documento. Las características que presentaba este espacio regional fueron objeto de diversas narraciones en las cuales se erotizaba su naturaleza. Poseía ríos anchos para que sobre ellos se dispongan vapores y así extraer las maderas, suelos llanos para el cultivo, en otras palabras, existían todos aquellos elementos necesarios para instalar el 'progreso'.

Con el propósito de llevar adelante esta tarea se justificaron una serie de acciones violentas que terminaron por promover un sentido común dominante donde el pueblo mapuche y sus costumbres fueron vistas como 'primitivas' o 'salvajes'. Esta construcción negativa del otro es fundamental para intentar dominar en nombre de una supremacía cultural (Dussel, 1994; Bhabha, 2002). En una carta enviada a las autoridades del país por el toqui MangilWenu, se plantea con preocupación los atropellos que se realizan al pueblo mapuche:

"El gobierno ha demarcado una provincia, traspasando el Biobío que abraza una parte considerable de nuestro territorio que actualmente habitamos (...) Todo asunto que tenga relación con terrenos, nadie puede por sí solo resolver sin que se haga junta general de los caciques que comprendan los cuatro Huitral-mapus ${ }^{4}$, y lo que resuelva la mayoría, esa es 
la ley" (MangilWenu. Carta al general Justo José de Urquiza. Territorio Indígena, abril 30 de 1860, en Pavez, 2008).

En esta misiva se plasma como el Estado chileno desconoce los tratados anteriores celebrados entre mapuches y españoles e invade este territorio, con el propósito de someter a sus habitantes y usurpar las tierras. Junto con ello, se promulgaron una serie de leyes orientadas al mismo objetivo:

"Fúndense poblaciones en los parajes del territorio de los indígenas que el presidente de la república designe (...) los sitios en que se dividan los terrenos destinados a poblaciones, se concederán gratuitamente a los pobladores (...) se auxiliará a los indígenas que quieran avecindarse en las nuevas poblaciones" (Ley de 1866. Sobre radicación y concesión de títulos de merced a los indígenas, Artículos 1 y 2)

Con estas reglas se instó a entregar tierras a los colonos, situación que requería tener un cierto 'stock' de suelos despejados para ser facilitados. A partir de la promulgación de esta ley, surgieron problemas por la propiedad de la tierra ya que los terrenos que el Estado puso a disposición tenían dueños, estaban habitados hace siglos por el pueblo mapuche. A partir de estos relatos se deja en evidencia que fue necesario también llevar a cabo una agresión sistemática que se funda en la violencia constante sobre los diversos ámbitos de la vida del pueblo mapuche. Estas acciones, junto con la explotación productiva de estas fértiles tierras, se constituyeron en los instrumentos idóneos para instalar el colonialismo en este lugar.

La coerción se materializo con mayor fuerza a través de la campaña militar de Cornelio Saavedra, conocida eufemísticamente como 'Pacificación de la Araucanía'. El propósito de ello fue poblar definitivamente este espacio, para lo cual el fuerte se transformaría en un pequeño asentamiento que permitiría controlar la 'barbarie' y promover la llegada de población 'civilizada', así sería viable impulsar el comercio y ocupar los terrenos colindantes para conformar el paisaje de poder del 'Granero de Chile'. Al respecto Saavedra señalaba:

"Construyendo pues cinco fuertes en los puntos que puede atravesarse el Malleco se dejarían casi en una completa incomunicación a las fuerzas indígenas organizadas" (Saavedra, 1870, p.11).

La geografía y la naturaleza que fue propicia para el habitar del pueblo mapuche, jugo en su contra ya que las riberas de los ríos y la altura de los cerros fueron propicias para asentar ahí algunas fortificaciones. En la figura $\mathrm{N}^{\circ} 2$ se incluye un mapa que da cuenta del uso del espacio por parte del pueblo mapuche. Los indios muluches o arribanos ocupaban el sector oriente asociado a las cordilleras de Pichinitrón y Galliruka, además, habitaban en los valles que se extienden desde el río Malleco al Cautín (A). Los indios abajinos se distribuían entre los arribanos y los costinos, abarcaban el sector central asociados a los valles que surgen entre los ríos Malleco y Cautín (B). Los indios costinos, se observan instalados en la costa de Arauco y Valdivia (C).

Estas tres agrupaciones (arribanos, abajinos y costinos) tenían como frontera sur, al río Cautín. En el interfluvio entre este río y el Toltén aparecen de oriente a poniente los indios de Llaima, de Trutru, de Maquehua, de Huiliu y de Boroa y de Imperial (D). Pasado el segundo límite natural 
que es el río Toltén, surgen las tribus de Pitrufquén, de Villarrica (E) y hacia la cordillera entre los lagos Villarrica y Calafquén las tribus de Panguipulli y, finalmente, en el extremo sur las tribus del Riñihue.

Este es el espacio que se desea controlar, entonces es necesario detallar cada lugar y, además, dar a conocer los fuertes que ya se han levantado en torno al río Malleco (línea continua ennegrecida). Así entonces, se nombran los fuertes de Huequén, Cancura, Lonlenco, Chihuaihue, Mariluan, Collipulli, Perasco y Curaco, ubicados en posición hacia la cordillera y los fuertes de Purén y Lumaco que Saavedra ya ha logrado construir y que estaban considerados en su plan. La línea se interna entre Abajinos y Costinos para seguir bajando hacia la Costa, cruzando el río Rehue, las vegas de Purén, el lago Lleulleu, que atraviesa el río Imperial hasta internarse en el lago Budi y seguir hacia el sur hasta donde se encuentra el fuerte de Toltén. Es ahí donde esta línea se adentra por el río Toltén y baja nuevamente en el fuerte Comuy hacia el sur. En su trayecto baja hacia el centro del territorio mediante otra línea diseñada más tenue, que corresponde a lo que falta para completar la defensa. Así continúa su recorrido por el río Toltén donde se indican los fuertes que Donguil, Pitrufquén y Villarrica, que es donde finaliza su trazado.

Figura 2.

Plano de Arauco y Valdivia con la designación de la antigua y nueva línea de frontera contra los indios, 1870. Construido por MJO.

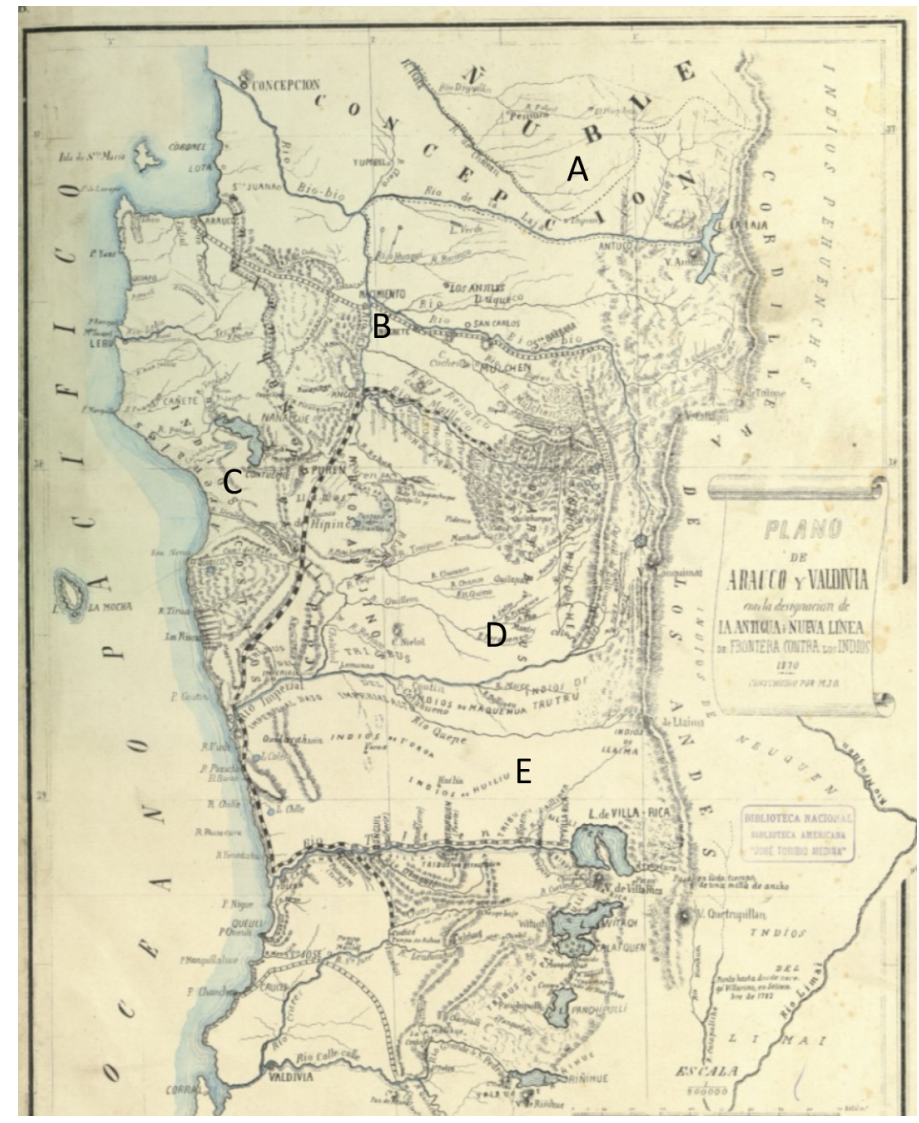

Fuente: Archivo Nacional. 
De alguna manera, el histórico conflicto Estado-Pueblo Mapuche por el que pasa la actual región de La Araucanía tiene su origen en acciones que se basan en estas diferencias culturales establecidas hace más de un siglo y que permanecen hasta nuestros días. Al igual que antaño, Wallmapu (Araucanía) sigue siendo explotada a partir de la búsqueda constante de nuevas 'vocaciones productivas'. Incluso la figura del 'salvaje' del siglo XIX ha sido reemplazada en el siglo XXI por 'terrorista', para referirse algunos comuneros mapuches que han sido encarcelados actualmente por procesos vinculados a la violencia rural.

\section{El paisaje de poder del 'Granero de Chile'}

En la medida que el Wallmapu (Araucanía) comenzaba a ser 'conquistado' por el Estado chileno, desde el nivel central y utilizando diferentes medios de comunicación, la elite agrícola de la época entregó orientaciones respecto a lo que ocurría en el mercado internacional del trigo, promoviendo así estos nuevos cultivos en aquellos terrenos del sur que estaban siendo ocupados. Son precisamente este tipo de estrategias las que permiten a las elites asumir la dirección cultural e ideológica hegemónica en una sociedad, ya que existe la conciencia de que sus intereses pueden y deben convertirse en los intereses de otros grupos subordinados (Portelli, 1979; Gramsci, 1999).

En este contexto, desde el Boletín de la Sociedad Nacional de Agricultura, Julio Menadier ${ }^{5}$ planteaba:

“Para qué sirven los inmensos tesoros diseminados de norte a sur de la república si no se les explota? (...) Si en las regiones apartadas la barbarie secular se halla todavía en pugna con la civilización improvisada, no pasarán muchos años sin que aquélla tenga que ceder delante de la inmigración y colonización" (Menadier, 2012, p. 40 y 548).

A juicio de Menadier sólo mediante la explotación de las tierras sería posible mejorar la economía del país y para ello era fundamental aumentar las hectáreas cultivables. Las condiciones naturales del país permitían ampliar hacia el sur la agricultura que se llevaba a cabo en las haciendas de la zona central. Las expectativas planteadas respecto a estas tierras fueron constantemente sustentadas en la información transmitida por algunos viajeros, quienes aprovechando la instalación de los fuertes y los incipientes centros poblados que comenzaban a formarse, visitaban este espacio regional y quedaban deslumbrados con su naturaleza. Uno de ellos fue Recaredo Tornero, quien planteaba:

"El aspecto general de este vasto territorio es grandioso y encierra inmensos tesoros que con el tiempo harán de él una de las regiones más ricas y productivas de Chile. Su abundante y espléndida vegetación ofrece bosques inagotables de ricas maderas de construcción (...) la feracidad del terreno y bondad del clima favorecen el cultivo del trigo" (Tornero, 1872 , p. 359)

El libro denominado La agricultura y el progreso de Chile de Julio Menadier editado por Rafael Sagredo Baeza en el año 2012, reúne una selección de artículos que Menadier escribió durante 1869 a 1886 en el Boletín de la Sociedad Nacional de Agricultura. Ver, Sección inicial del libro escrita por Claudio Robles. Julio Menadier: un ideólogo agrario en la esfera pública, páginas IX-LIII. 
El escenario descrito se ajusta a lo esperado por Menadier. Las tierras de la antigua frontera eran propicias no tan solo para el cultivo de trigo, sino que también para la explotación maderera. No obstante, para llevar adelante este proceso era necesario instalar una organización política administrativa adecuada que resguardara a aquellos capitalistas que quisieran probar suerte en este lugar. Algunos avances ya se habían dado en este sentido con la creación en 1869 de los Departamentos de Angol e Imperial que establecieron los límites en este espacio regional (González y Bernedo, 2013). La creación del Territorio de colonización de Angol en 1875 vino a reafirmar este proceso que culminaría en 1887 con la creación de las provincias de Malleco y Cautín.

Con Wallmapu (Araucanía) bajo resguardo militar, se comenzaron a comunicar a la sociedad nacional y regional noticias positivas respecto al avance de las acciones civilizatorias sobre el territorio araucano. Los censos jugaron un rol fundamental en este sentido, ya que se transformaron en herramientas de control para el monitoreo de la población, además, permitieron divulgar el desarrollo productivo que ocurría en estas tierras y también contribuyeron a difundir una imagen bélica del pueblo mapuche. Al respecto, el Censo publicado en 1875 indicaba lo siguiente:

"El departamento de Angol se halla ocupado aún en su mayor parte por los indígenas, concentrándose la población civilizada en la región del norte (...) Aunque sujeta a mil contingencias la industria agrícola de Angol, a causa de la inseguridad de los campos amenazados por las excursiones frecuentes de los araucanos, ha alcanzado, un desarrollo considerable (...) En pocos meses más habrá de contar también con una línea férrea de vapor que actualmente se construye y que lo pondrá en comunicación con las provincias del centro hasta Valparaíso. Este será un gran paso para el desarrollo de estas nacientes poblaciones, y una prenda segura de su prosperidad futura" (Censo,1875, p. 111-113).

Esta reseña es otra muestra más del colonialismo interno que ocurrió en este lugar. Las denominaciones negativas respecto del 'otro' -incivilizado, salvaje, bárbaro- contribuyeron a que la cultura mapuche fuera percibida como inferior con el propósito de lograr su sometimiento. Estas acciones se enmarcan en "el intento de dominar en nombre de una supremacía cultural" (Bhabha, 2002, p. 55).

El desarrollo de la industria es otro elemento que destaca el censo, al igual que el pronto arribo del ferrocarril. Este documento se alinea con las descripciones anteriores realizadas por la elite intelectual (naturalistas, viajeros, cronistas) ya que observan la prosperidad que este lugar puede alcanzar en la medida que continúe siendo objeto de profundas transformaciones. El paisaje de poder del 'Granero de Chile', sería el símbolo de ellas.

Para explotar estas tierras, la usurpación de ellas al pueblo mapuche resulto fundamental. En esto contribuyó la ley promulgada el 4 de diciembre del año 1866, que ordenaba deslindar los terrenos pertenecientes al pueblo mapuche y otorgar un Título de Merced sobre predios rurales. Este proceso se hizo efectivo en 1883 con la creación de la Comisión Radicadora de Indígenas cuyo objetivo consistió en radicar a los indígenas en espacios delimitados (Informe de la comisión verdad histórica y nuevo trato con los pueblos indígenas, 2003). Entre 1884 y 1929 esta comisión asignó 504.778,4 hectáreas distribuidas en 3.078 reducciones, las tierras donde fueron localizados eran de mala calidad y se ubicaban en zonas costeras y cordilleranas (Almonacid, 2009; Chihuailaf, 2014). Solo entre 1884 y 1900 se entregaron cerca de 718 mercedes de tierra (Figura $\mathrm{N}^{\circ} 3$ ). 
Figura 3.

Número de títulos de merced entregados. 1884-1900

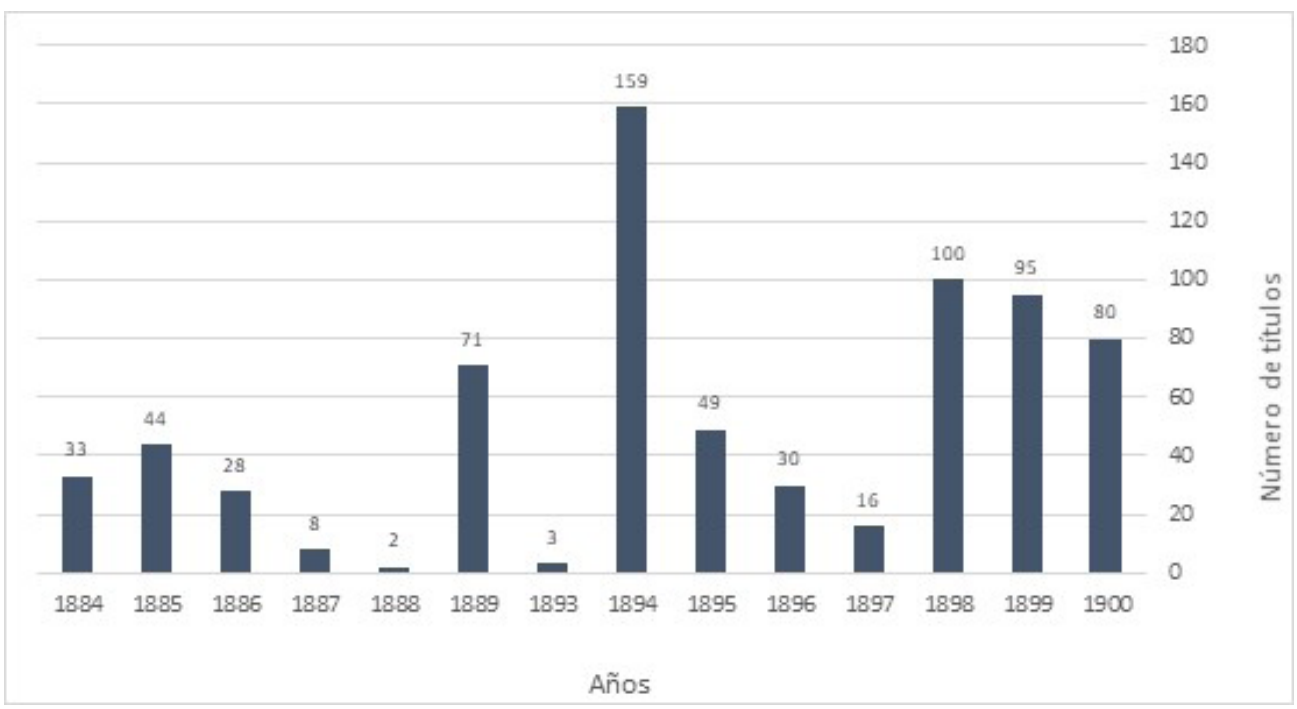

Fuente: Oficina de tierras. CONADI Región de La Araucanía (2018)

Este proceso representa la 'acumulación primitiva' que se llevó a cabo en este territorio y que se caracterizó por la extracción de las riquezas provistas por la naturaleza araucana que permitió la acumulación de capital y la constitución de la propiedad privada, a los nuevos habitantes que arribaron a este espacio regional (Klubock, 2014; Pinto et al, 2015). Las grandes y extensas tierras mapuches fueron fragmentadas y se transformaron en 'unidades productivas'. Este cambio permitió mantener el control sobre las tierras ya que fue posible conocer con certeza las características de cada predio, es decir, el propietario, la superficie disponible para la explotación y el rendimiento factible de alcanzar.

La expresión territorial de las relaciones de poder que durante este período promovidas desde una hegemonía imperante, se encuentra representada por la desposesión que ocurre con las tierras mapuches. El hecho de trasladarlos a sectores periféricos permitió que las mejores tierras quedaran disponibles para los colonos y hacendados de la zona central del país, quienes se trasladaron a este lugar para asegurar la explotación de estas tierras y formar parte del paisaje de poder del 'Granero de Chile'.

\section{El 'gigante de acero'}

La llegada del ferrocarril a Wallmapu (Araucanía) se inició con la construcción de la línea hacia Angol y el ramal a Los Ángeles en 1873, luego en 1884 y bajo el gobierno de Domingo Santa María, el ferrocarril se extiende desde Angol a Traiguén y de Renaico a Victoria (Marín, 1901). La llegada del tren permitió movilizar la producción de trigo al interior del 'anillo' de fortificaciones y comercializarlo en los centros poblados que empezaron surgir de los antiguos fuertes militares. La construcción de la línea férrea trajo consigo también la construcción de viviendas al costado de las vías, las cuales contribuyeron al origen de las ciudades (Ovalle, 1912). 
El ingeniero belga Gustave Verniory, tuvo a su cargo gran parte de la construcción de las vías y puentes ferroviarios de la región. Durante su estadía en este lugar (1889-1899) escribió y fotografió los cambios que el ferrocarril introdujo en este territorio. El trazado imponente que se construyó para dar cabida a este 'gigante de acero' penetró hasta los lugares más recónditos, surcando sin obstáculos aquellas barreras naturales que presentaba la naturaleza araucana. Verniory, de alguna manera personifico aquel saber técnico-ingenieril que provenía de las sociedades más 'avanzadas' y que resulto crucial para conectar este territorio a los centros metropolitanos, materializando así el anhelo de la elite agrícola del país e inicio con ello el extractivismo en la antigua frontera.

Uno de los hitos relevantes que fotografió fue el Viaducto del Malleco inaugurado en 1890. Este puente de gran magnitud se constituyó en un símbolo del progreso y fue un enlace perfecto para trasladar la producción de trigo que se generaba en estas fértiles tierras hacia Concepción y Valparaíso. La figura $\mathrm{N}^{\circ} 4$, complementa las fuentes documentales y mapas anteriormente expuestos y agrega una dimensión de la realidad y cotidianeidad que ocurría mientras se construía el Granero de Chile, en ella se presenta como tema central el viaducto en todo su esplendor, no obstante, al realizar una lectura más detallada es posible reconocer en la parte superior de la imagen los molinos y bodegas del acaudalado empresario del trigo José Bunster, mientras que en la sección inferior de la figura se observan carretas y pequeñas construcciones habitacionales. Esta imagen refleja los contrastes y diferencias sociales que surgían en la medida que se instalaba este paisaje'.

Figura $\mathrm{N}^{\circ} 4$.

Puente de Malleco a Collipulli.

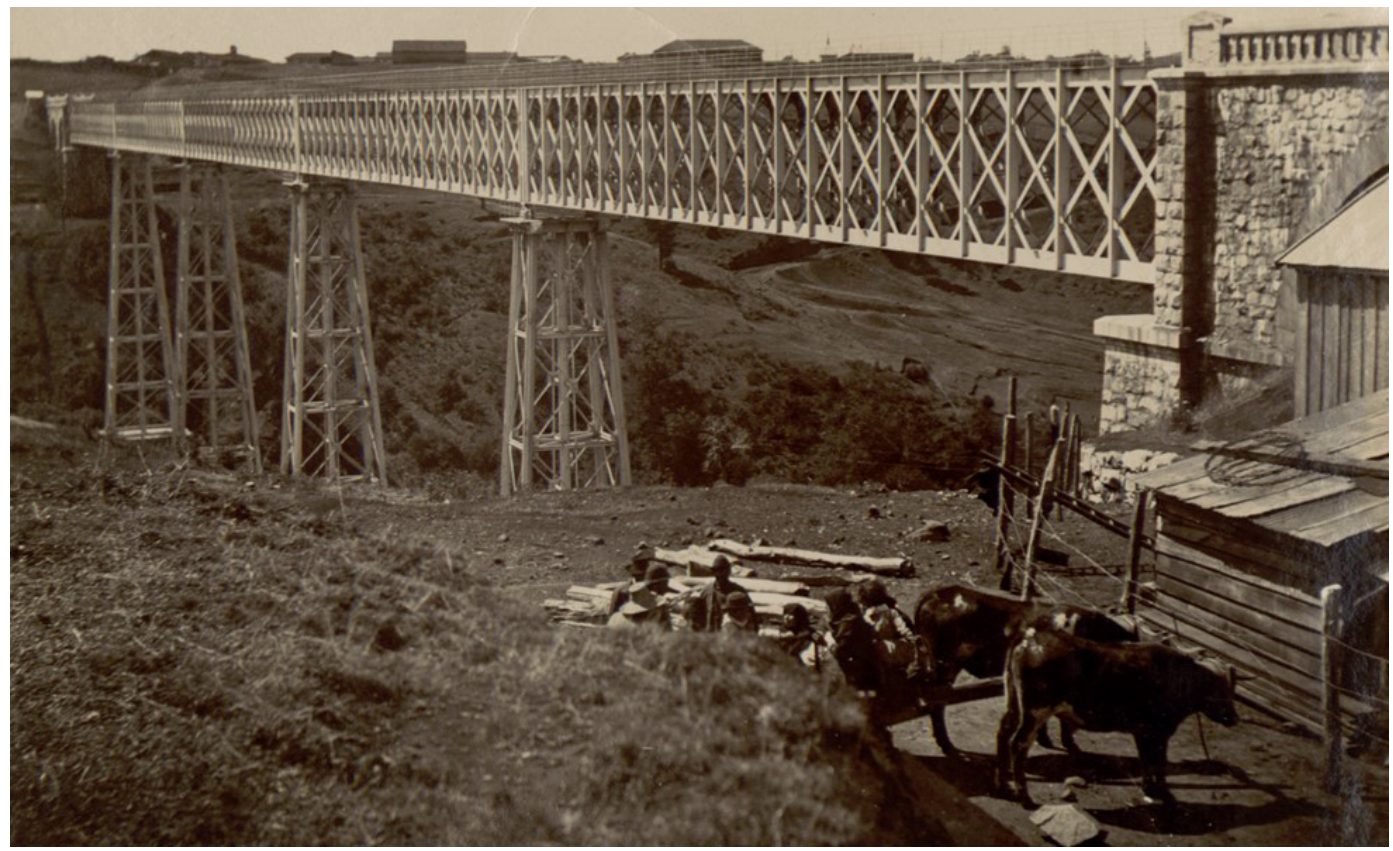

Fuente: Colección Gustave Verniory. Colección fotográfica. Musée du QuiaiBranly Jacques Chirac. 
El ferrocarril continuó extendiéndose por toda la provincia de Malleco. Se construyeron ramales y estaciones que posibilitaron que el tren pudiera conectar aquellos intersticios cercanos a los campos que tenían una producción importante de cereales. Esto permitió asegurar el traslado de los granos hacia las principales capitales departamentales y con ello dar vida a los molinos que contribuían a la economía local y al crecimiento urbano (Cuadro №1).

Cuadro N¹.

Ramales construidos en la provincia de Malleco.

\begin{tabular}{|l|c|c|}
\hline \multirow{2}{*}{ Estación } & \multicolumn{2}{|c|}{ Distancia } \\
\cline { 2 - 3 } & Parcial $(\mathrm{km})$ & Total $(\mathrm{km})$ \\
\hline Renaico & 0 & 0 \\
\hline Roblería & 3 & 3 \\
\hline Angol & 18 & 21 \\
\hline Trinte & 18 & 39 \\
\hline Sauces & 13 & 52 \\
\hline Quilquén & 21 & 73 \\
\hline Trigal & 9 & 82 \\
\hline Traiguén & 11 & 93 \\
\hline
\end{tabular}

Fuente: Elaboración propia en base a Espinoza, 1897.

El avance tecnológico que alcanzó el ferrocarril en estos tramos permitió que años más tarde por las tierras de La Araucanía se movilizara uno de los primeros tranvías eléctricos de América Latina. Esta máquina instalada en la ciudad de Traiguén posibilitó el transporte de carga desde la estación de ferrocarriles hacia el Molino El Globo de José Bunster ubicado próximo al río.

La figura $\mathrm{N}^{\circ} 5$ entrega otra dimensión para analizar la conformación de este paisaje, específicamente muestra la construcción de la línea férrea entre Victoria y Temuco (sector de Quillem) que

Figura $\mathrm{N}^{\circ} 5$.

Entrada a la gran trinchera de Quinquel.

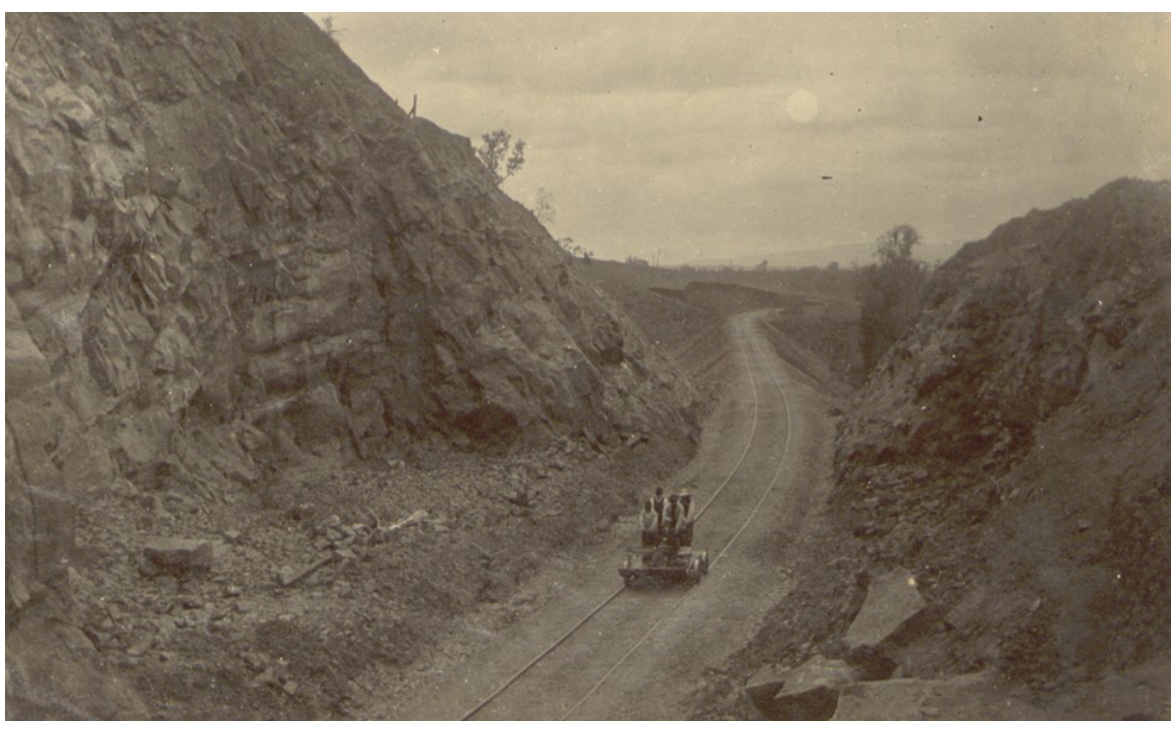

Fuente: Colección Gustave Verniory. Musée du QuiaiBranly Jacques Chirac. 
implicó la apertura de nuevos ensanches sobre cerros y montañas, los cuales fueron realizados para acoger las líneas férreas que se introducen hasta los lugares más recóndito. El propósito de continuar ampliando el tramo ferroviario tuvo como objetivo que ningún espacio quedara sin explotar.

La transformación territorial que ocurre en esta época no fue casual. El paisaje de poder del 'Granero de Chile' se construye sobre un saber científico-técnico que se traduce en un corto tiempo en la promulgación de leyes, la usurpación de la tierra y el financiamiento de grandes obras de infraestructura que, junto con posicionarse como símbolos del 'progreso' permitieron asegurar el control de este espacio para la llegada de empresarios a explotar las tierras. De alguna manera, estas obras permitieron invisibilizar las costumbres y las formas de habitar del pueblo mapuche, transformándose en dispositivos propicios para promover acciones de violencia epistémica y representacional.

\section{Las 'ciudades europeas'}

El Estado chileno instalado en Wallmapu (Araucanía) promovió la supremacía de la ciudad sobre el campo. La ciudad, junto con evitar la dispersión de la población, tuvo como objetivo también mantenerla bajo control a través de la burocracia administrativa que se instalaba en su interior (De Ramón, 1992). Las líneas defensivas establecidas por los fuertes y los ramales ferroviarios permitieron aglomerar población y movilizarla hacia aquellos espacios donde se concentraba la producción de trigo, 'modernizando' y 'sustituyendo' la forma de habitar que el pueblo mapuche llevaba a cabo en este lugar. Este ha sido precisamente el rol que han jugado las ciudades a lo largo de la historia, ya que se han constituido en espacios de transición al capitalismo, producen valor, pero no lo controlan (Moore, 2003). En el caso de las ciudades chilenas, desde el siglo XVII se transformaron en un foco de irradiación 'civilizadora' (Guarda, 1968).

Entre 1875 y 1895 la información extraída de los censos de la época muestra un proceso de urbanización de carácter explosivo para las ciudades de Angol, Traiguén, Victoria y Collipulli. Este proceso demográfico ascendente se sustentó en la producción de trigo que ocurría en los espacios rurales y su comercialización, que favoreció la fundación de nuevas ciudades (Traiguén, Victoria, Ercilla) (Cuadro $\mathrm{N}^{\circ} 2$ ). Este aumento de población se debió también al inicio de la colonización araucana, que durante 1882 y 1890 posibilitó el arribo de 1.531 familias, con un total de 7.120 personas (Censo, 1895).

Cuadro $\mathrm{N}^{\circ} 2$.

Población urbana de algunos poblados de la provincia de Malleco

\begin{tabular}{|l|c|c|c|}
\hline Ciudades & Censo 1875 & Censo 1885 & Censo 1895 \\
\hline Angol & 3.845 & 6.331 & 7.056 \\
\hline Collipulli & 1.722 & 4.043 & 3.227 \\
\hline Traiguén & $*$ & 2.981 & 5.732 \\
\hline Victoria & $*$ & 2.550 & 6.989 \\
\hline Los Sauces & 280 & 1.116 & 1.146 \\
\hline Purén & 457 & 560 & 1.077 \\
\hline Lumaco & 657 & 526 & 1.007 \\
\hline Ercilla & $*$ & 1.321 & 1.450 \\
\hline
\end{tabular}

Fuente: Elaboración propia a partir de Censo de 1875-1895.

${ }^{*}$ ) Las ciudades de Traiguén, Victoria y Ercilla fueron fundadas en 1878, 1881 y 1885, respectivamente. 
La figura $\mathrm{N}^{\circ} 6$ muestra como en un corto periodo de tiempo la imagen urbana que predominaba en estas nacientes ciudades era de una arquitectura europea, influenciada por la colonización y el arribo de una elite agrícola. Las casas y molinos en Traiguén, Angol y Collipulli se constituyeron también en 'símbolos' de progreso y riqueza, quedando plasmados en el paisaje de poder del 'Granero de Chile' (Figura Nº6).

Figura $\mathrm{N}^{\circ} 6$.

Ciudad de Traiguén, primeras décadas del siglo XX.

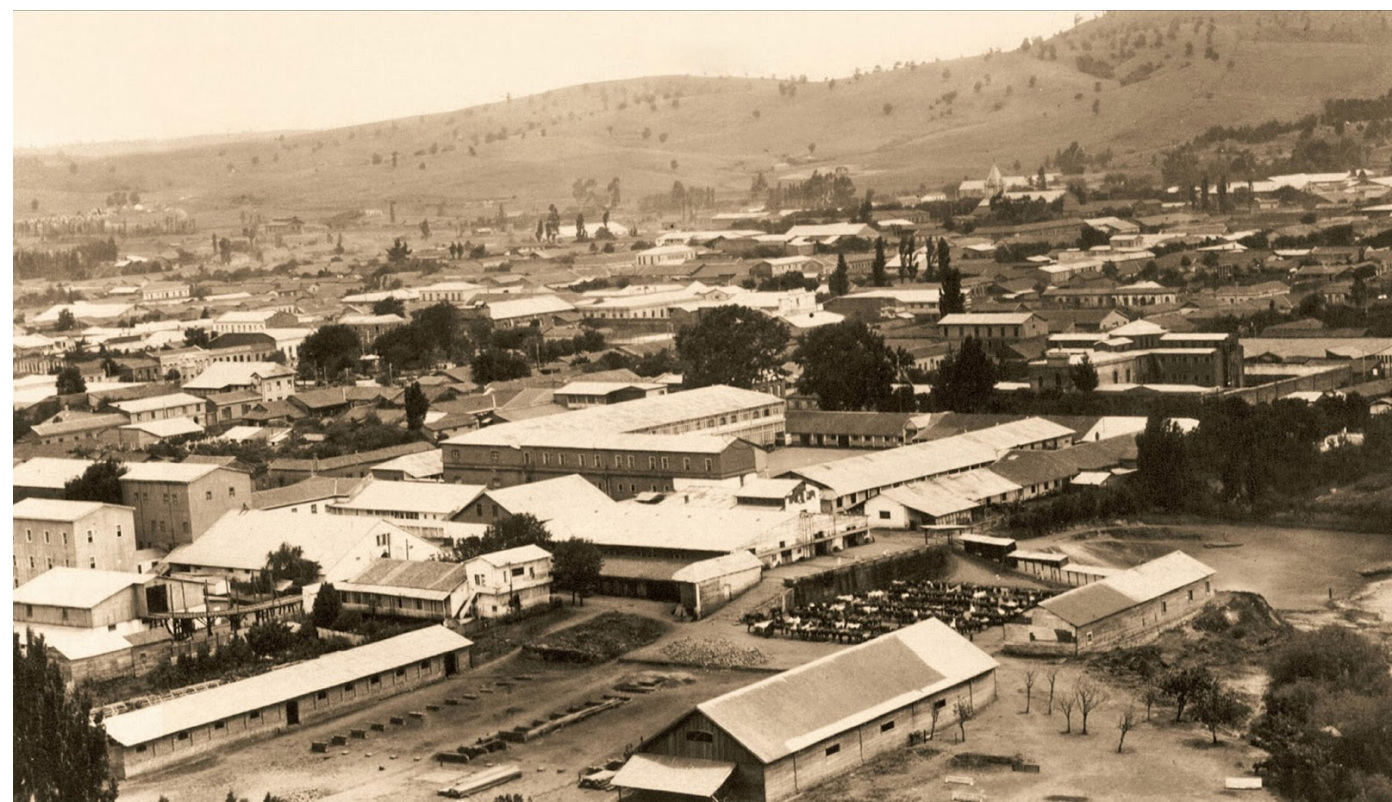

Fuente: Extraída de Ricardo Herrera Flody. Centenario de 1910. Provincias y comunas de Chile, Viña del Mar, Chile.

En la medida que las ciudades avanzaban, también lo hacían los procesos productivos asociados a la molienda de trigo. Los molinos de Bunster se constituyeron en piezas claves para la explotación de trigo entre Angol y Traiguén y su nivel tecnológico se describía de la siguiente manera:

"El establecimiento de molienda del señor Manuel Bunster es uno de los mejor montados (...) es de cilindros automáticos, pudiendo elaborar diarios hasta 200 quintales de harina de la mejor calidad. Posee alumbrado de luz eléctrica en todos sus departamentos (Mansoulet, 1898, p. 12).

El hecho que fuera posible contar con este tipo de artefactos, permitió que las tierras ubicadas al interior de la antigua frontera contribuyeran a aumentar significativamente la producción de quintales de trigo a nivel nacional. Esta bonanza trajo como consecuencia que las ciudades se transformaran en un epicentro de las actividades comerciales del sur del país. Una de las ciudades donde se concentró la actividad financiera producto de la riqueza agrícola fue Traiguén, Mansoulet la describía de la siguiente forma:

"Reputada como plaza comercial de primer orden, esta población justifica su fama por el extraordinario movimiento mercantil que en ella se desarrolla, principalmente en la época 
de la recolección de cereales (...) La industria molinera cuenta en Traiguén con tres establecimientos de primer orden pertenecientes a los señores José Bunster, Lavín y Urmeneta, Rogers y Pimentel" (Mansoulet, 1898, p. 24).

Si bien la producción de trigo fue decayendo durante las primeras décadas del siglo XX, debido a una recesión en los rendimientos de trigo producto del deterioro de los suelos debido a la producción intensiva de cereales. Se inició la construcción de un nuevo paisaje de poder durante gran parte del siglo XX, asociado a la explotación forestal y que sería conocido como el 'Oro verde', conformando así una trayectoria histórica de desposesión (Escalona 2019; Escalona \& Barton, 2020; Escalona, 2020).

\section{Conclusión}

Los territorios son construidos y reconstruidos en el tiempo. Las definiciones y precisiones sobre usos y vocaciones son construcciones sociales, formadas e impuestas a través de distintas configuraciones de relaciones de poder. En ocasiones son presentadas como una evolución casi lineal, de sentido común en la construcción del estado-nación y su progreso/desarrollo. En contraste con esta perspectiva o lectura acrítica, que refleja precisamente la narrativa dominante o hegemónica detrás de una particular construcción, el propósito de este artículo es presentar paisajes como construcciones socio-políticas, producidas a través de la imposición de ideas y formas (de modos de vida, de usos) por sobre otras. Un paisaje siempre refleja relaciones de poder, históricas y contemporáneas. Por lo mismo, puede ser redefinido y reconstruido; no es fijo.

Debatir sobre las concepciones tradicionales referidas al estudio del paisaje, resulta crucial para proponer nuevas interpretaciones. Por ello una de las contribuciones de este trabajo ha sido plantear una forma diferente de comprender el paisaje a partir de sus vínculos con el poder-paisajes de poder- los cuales proporcionan una herramienta útil para analizar la trayectoria espacio-temporal que han seguido las transformaciones territoriales del Wallmapu (Araucanía).

El paisaje de poder del 'Granero de Chile' emerge como un 'símbolo' de la hegemonía del Estado y las elites de la época quienes promovieron la explotación productiva de estas tierras mediante diversos dispositivos: promulgación de leyes, la usurpación de la tierra al pueblo mapuche. Para indagar en ello resulto clave el análisis e interpretación de fuentes documentales, pero también de mapas y fotografías, que entregaron una dimensión más próxima a la realidad y la cotidianeidad que ocurría en este espacio regional mientras se construía este paisaje. Estas fuentes revelan las formas de crear, convencer, coartar y finalmente imponer un paisaje basado en una narrativa de progreso nacional, negando y eliminando un paisaje mapuche preexistente en el proceso. 'Borrón y cuenta nueva' ha sido la forma de crear paisajes en territorios chilenos desde la colonia. Estas son las construcciones hegemónicas de paisaje, pero no son las únicas. Las otras alternativas que han co-existido o han sido destruidas, forman parte también de la geografía histórica chilena.

El Granero de Chile fue la primera experiencia de gran escala realizada por el naciente Estado chileno en construir un paisaje productivo. Este paisaje abrió la senda al extractivismo en este lugar y también al 'progreso' tan anhelado por las elites agrícolas, científicas y políticas del país. 
No obstante, bajo el resplandor de las pujantes ciudades y rápidas locomotoras que surcaban el granero, se escondieron constantes atropellos hacia el pueblo mapuche. Situación similar ocurre en la actualidad, donde la búsqueda de nuevas vocaciones productivas ha permitido la instalación de otros paisajes de poder: la actividad forestal, el turismo y la fruticultura, que se han transformado en el bastión de las políticas que han impulsado el 'desarrollo' regional durante el siglo XX, pero que replican las mismas lógicas que el Granero. Estas construcciones sociales hegemónicas son enfocadas en una narrativa de desarrollo nacional basada en paisajes productivos que no distinguen entre culturas, modos de vida y distintas conceptualizaciones de desarrollo sustentable, o un buen vivir. Es por eso que los paisajes deben ser leídos como paisajes de poder y no solamente paisajes fenomenológicos materiales e inmateriales, ausentes de conflictos. El conflicto actual en esta región es el legado de este proceso histórico de construcción e imposición de paisajes productivos.

\section{Bibliografía}

ALMONACID, F. El problema de la propiedad de la tierra en el sur de Chile (1850-1930), Historia, 2009, $\mathrm{N}^{\circ} 42$, Vol. 1, p. 5-56.

BARTHES, R. Lo obvio y lo obtuso. Imágenes, gestos y voces. Barcelona: Paidos, 1986.

BENGOA, J. Historia del pueblo mapuche: (siglo XIX y XX). Santiago: LOM, 2000.

BAUER, A. Expansión económica en una sociedad tradicional: Chile central en el siglo XIX. Santiago: Universidad Católica de Chile, 1970.

BHABHA, H. El lugar de la cultura. Buenos Aires: Manantial, 2002.

BURKE, P. Visto y no visto. El uso de la imagen como documento histórico. Barcelona: Critica, 2001.

CARIOLA C. \& SUNKEL O. Un siglo de historia económica de Chile. 1830-1930. Dos ensayos y una bibliografía. Madrid: Cultura hispánica, 1982.

CASSIRER, E. Las ciencias de la cultura. México: Fondo de Cultura Económica, 2014.

CENSO GENERAL DE LA REPÚBLICA DE CHILE. Levantado el 19 de abril de 1875. Santiago de Chile. Imprenta Nacional.

CENSO GENERAL DE LA REPÚBLICA DE CHILE. Levantado el 26 de noviembre de 1885. Tomo Primero. Valparaíso. Imprenta La Patria, 1885.

CENSO GENERAL DE LA REPÚBLICA DE CHILE. Levantado el 28 de noviembre de 1895. Tomo Cuarto. Valparaíso. Imprenta del Universo, 1895.

COSGROVE, D. y DANIELS, S. The iconography of landscape: Essays on the Symbolic Representation, Design and Use of past Environments. Cambridge: University Press, 1988. 
CHIHUAILAF, A. El Estado chileno y la región de la Frontera a fines del siglo XIX, Amérique Latine Histoire et Mémoire. Les Cahiers ALHIM [En línea], 28, 2014. Disponible en internet: http://journals. openedition.org/alhim/5108

DAVIS, D. Historical political ecology: On the importance of looking back to move forward. Geoforum, 2009, Vol. 40, №3, p. 285-286.

DAVIS, D. Historical approaches to political ecology. En: BRIDGE, G, MCCARTHY, J. y PERRAULT, T. The handbook of political ecology. New York: Routledge, 2015, p. 263-275.

DAVIS, D. The Arid Lands: History, power, knowledge. Cambridge: MIT Press, 2016.

DE OVALLE, A. Histórica relación del Reyno de Chile y de las misiones y ministerios que exercita en el la Compañía de Jesús. Impreso en Roma por Francisco Caballo, 1646.

DE RAMÓN, A. Urbanización y dominación. Reflexión acerca del rol de las ciudades en América Latina (1535-1625). Boletín de historia y geografía, 1992, №12, p. 5-31.

DEL CASINO, V. \& HANNA, S. Beyond the Binaries: A Methodological Intervention for Interrogating Maps as Representational Practices. International E-Journal for Critical Geographers, 2006, Vol.1, $\mathrm{N}^{\circ} 4$, p. 34-56.

DOMEYKO, I. Araucania y sus habitantes. Santiago: Imprenta chilena, 1846.

DONNELLY, M. y NORTON, C. Doing history. London-New York: Routledge, 2011.

DUSSEL, E. El encubrimiento del otro. Hacia el origen del mito de la modernidad. Ecuador: Ediciones Abya-Yala, 1994.

ELIZALDE, R. La sobrevivencia de Chile. Santiago: Ministerio de agricultura, 1958.

ESCALONA ULLOA, M. Paisaje, poder y transformaciones territoriales en Araucanía, 1846-1992:Una ecología política histórica. Tesis de grado para optar al título de Doctor en Arquitectura y Estudios Urbanos. Facultad de Arquitectura, Diseño y Estudios Urbanos. Pontificia Universidad Católica de Chile, 2019

ESCALONA ULLOA, M. y BARTON J. A 'Landscapes of Power' framework for historical political ecology: The production of cultural hegemony in Araucanía-Wallmapu. Area, 2020, Vol. 52, $\mathrm{N}^{\circ} 2$, p. 445-454. https://doi.org/10.1111/area.12591.

ESCALONA ULLOA, M. (2020). Transformaciones territoriales en Wallmapu/Araucanía. Una ecología política histórica. En Escalona Ulloa M., Muñoz-Pedreros A., \& Figueroa Hernández D., (eds.) Gobernanza ambiental. Reflexiones y debates desde La Araucanía, (pp. 19-70). Santiago: RIL Editores.

ESPINOZA, E. Geografía descriptiva de la república de Chile. Santiago: Barcelona, 1897. 
FEMIA, J. Gramsci's political thought. New York: Clarendon Press, 1987.

FOUCAULT, M. El juego de Michel Foucault: en Saber y verdad. Madrid: Ediciones de la Piqueta, 1984.

GONZÁLEZ, J. \& BERNEDO, P. Cartografía de la transformación de un territorio: La Araucanía 18521887. Revista de geografía Norte Grande, 2013, №54, p. 179-198. https://dx.doi.org/10.4067/S071834022013000100010

GUARDA, G. La ciudad chilena del siglo XVIII. Buenos Aires: Centro editor de América Latina, 1968.

GRAMSCI, A. Cuadernos de la cárcel. Tomo 5. México: Era Ediciones, 1999.

GREZ, S. De la "regeneración del pueblo" a la huelga general: génesis y evolución histórica del movimiento popular en Chile (1810-1890). Santiago: RIL Editores, 2007.

HARLEY, J. Deconstructing the Map. Cartographica, 1989, Vol. 26, N², p. 1-20.

HUMUD, C. Política económica chilena desde 1830 a 1930. Estudios de Economía, 1947, Vol. 1(1), $1-123$.

HUSSERL, E. Ideas, relativas a una fenomenología pura y una filosofía fenomenológica. México: Paidos, 1962.

Informe de la Comisión Verdad Histórica y Nuevo Trato con los Pueblos Indígenas. Entregado al Presidente Ricardo Lagos, el 28 de Octubre de 2003. Disponible en internet: http://bibliotecadigital.indh.cl/handle/123456789/268

INGOLD, T. The Temporality of the Landscape. World Archaeology, 2003, Vol. 25, №2, p. 152-174 p.

KIPPING, M. WADHWANI, D. y BUCHELI, M. Analyzing and Interpreting Historical Sources: A Basic Methodology. En BUCHELI, M. y WADHWANI, D. Organizations in Time: History, Theory, Methods. Oxford: Oxford University Press, 2014, p. 306-329.

KOSSOY, B. Fotografía e Historia. Buenos Aires: ARBN, 2001.

KLUBOCK, T. La frontera. Forests and ecological conflict in chile's frontier territory. Durham and London: Duke University Press, 2014

LEY de 1866. Sobre radicación y concesión de títulos de merced a los indígenas

LOWENTHAL, D. Geography, experience, and imagination: towards a geographical epistemology. Annals of the Association of American Geographers, 1961, Vol. 51, No. 3, p. 241-260. 
MANSOULET, J. Guía-crónica de la frontera araucana de Chile. Años 1892-93. Santiago de Chile: Editorial e imprenta Barcelona, 1893.

MARÍN, S. Estudio de los ferrocarriles chilenos. Santiago: Imprenta Cervantes, 1901.

MARTIN, J. The political logic of discourse: A neo Gramscian view history of European. Ideas, 2002, Vol. 28, p. 21 -31. https://doi.org/10.1016/S01916599(02)00004-9

MEINIG, D. The interpretation of ordinary landscapes. New York: Oxford University Press, 1979.

MEMORIA DE LA INSPECCIÓN GENERAL TIERRAS Y COLONIZACIÓN. Santiago: Imprenta nacional, 1903

MENADIER, J. La agricultura y el progreso de Chile (1869-1886). Santiago: CCHC-PUC-DIBAM, 2012.

MITCHELL, D. The lure of the local: landscape studies at the end of a troubled century. Progress in Human Geography, 2001, Vol. 25, N², p. 269-281.

MITCHELL, D. Cultural landscapes: the dialectical landscape-recent landscape research in human geography. Progress in Human Geography, 2002, Vol. 26, N³, p. 381-389.

MITCHELL, D. New axioms for reading the landscape: Paying attention to political economy and social justice. En: WESCOAT, J y JOHNSTON, D. Political economies of landscape change. The Nederlands: Springer, 2008, p. 29-50.

MOESBACH, W Vida y costumbre de los indígenas araucanos en la segunda mitad del siglo XIX. Santiago, Imprenta Universitaria, 1930.

MOORE, J. La Naturaleza y la Transición del Feudalismo al Capitalismo. Traducido de "Nature and the Transition from Feudalism to Capitalism," Review, 2003, Vol. 26, №2, p. 97-172.

MUIR, R. Landscape: A Wasted Legacy. Area, 1998, Vol. 30, N³, p. 263-271.

OFFEN, K. Historical Political Ecology: An Introduction. Historical Geography, 2004, Vol. 32, p. $19-42$.

ORTEGA, L. Los empresarios, la política y los inicios de la guerra del pacífico. FLACSO, 1984, No. 24, 1-81.

OVALLE, F. Por el sur de Chile. Civilización desconocida. Santiago: La llustración, 1912.

PAVEZ, J. Cartas Mapuches del siglo XIX. Santiago: Ocho libros, 2008.

PINTO, J. La formación del Estado y la nación, y el pueblo mapuche. Santiago: Dibam, 2003. 
PINTO, J. La formación del Estado y la nación, y el pueblo mapuche. Santiago: Dibam, 2003.

PINTO, J. GOICOVICH, I. PAIRICAN, F. CANIUQUEO, S. DEL VALLE, C. MARIMAN, J. LLAITUL, H. Conflictos étnicos, sociales y económicos: Araucanía 1900-2014. Santiago: Pehuén, 2015.

POPPER, K. Conjeturas y refutaciones. El desarrollo del conocimiento científico. México: Fondo de Cultura Económica, 1991.

PORTELLI, H. Gramsci y el bloque histórico. México: Siglo XXI, 1979.

ROBLES, C. La producción agropecuaria chilena en la "era del salitre" (1880-1930). América Latina en la historia económica, 2009. No. 32, 131-134.

RYDIN, Y. Conflict, consensus, and rationality in environmental planning. An institutional discourse approach. New York: Oxford University Press, 2003.

SAAVEDRA, C. Documentos relativos a la ocupación de Arauco que contienen los trabajos practicados desde 1861 hasta la fecha. Santiago: Imprenta de la libertad, 1870.

SAUER, C. The Morphology of Landscape. En: LEIGH, J. Land \& Life. A selection from the writings of Carl Ortwin Sauer. Berkeley:University of California Press. 1925, p. 315-350.

SIMMEL, G. Filosofía del paisaje. Madrid: Casimiro Libros, 2012

SCHLÖGEL, K. En el espacio leemos el tiempo. Sobre historia de la civilización y geopolítica. España: Ediciones Siruela, 2007.

TORNERO, R. Chile ilustrado. Guía descriptivo del territorio de Chile, de las capitales de provincia y de los puertos nacionales. Valparaíso: Librerías y agencias del mercurio, 1872.

TUAN, YI FU. Topofilia. Un estudio de las percepciones, actitudes y valores sobre el entorno. Madrid: Melusina, 1974.

VERMEYLEN, S. DAVIES, G. y VAN DER HORST, D. Deconstructing the Conservancy Map: Hxaro, N!ore, and Rhizomes in the Kalahari. Cartographica, 2012, Vol. 47, №2, p. 121-134.

VERNIORY, G. Diez años en Araucanía, 1889-1899. Santiago de Chile: Pehuén, 2001.

VICUÑA MACKENNA, B. Discurso pronunciado a la Cámara de Diputados en su sesión del 10 de agosto de 1868. Santiago: Imprenta del ferrocarril, 1968. 